\title{
1 Comparative analysis of hissing calls in five tit species
}

2 Li Zhang ${ }^{1}$, Jianping $\mathrm{Liu}^{2}$, Zezhong Gao ${ }^{1}$, Lei Zhang ${ }^{1}$, Dongmei Wan ${ }^{1,}$, Wei

$3 \quad$ Liang $^{2, *}$, Anders Pape Møller ${ }^{3}$

$4 \quad{ }^{1}$ Key Laboratory of Animal Resource and Epidemic Disease Prevention,

5 College of Life Sciences, Liaoning University, Shenyang 110036, China

$6{ }^{2}$ Ministry of Education Key Laboratory for Ecology of Tropical Islands,

7 College of Life Sciences, Hainan Normal University, Haikou 571158, China

$8{ }^{3}$ Ecologie Systématique Evolution, Université Paris-Sud, CNRS,

9 AgroParisTech, Université Paris-Saclay, F-91405 Orsay Cedex, France

10 Email address:

11 LZ, lndxzl@outlook.com, ID: 0000-0003-1224-7855

12 JL, liujp@ hainnu.edu.cn, ID: 0000-0001-6526-8831

13 ZG, liaodagaozezhong@outlook.com

14 LZ, zhangl@lnu.edu.cn, ID: 0000-0003-2328-1194

15 DW, wandongmei@lnu.edu.cn, ID: 0000-0002-1465-6110

16 WL, liangwei@ hainnu.edu.cn, ID: 0000-0002-0004-9707

17 APM, anders.moller@u-psud.fr, ID: 0000-0003-3739-4675

Word count: 4571

*Corresponding author. DW (wandongmei@lnu.edu.cn), WL

(liangwei@hainnu.edu.cn)

Running headline: Hissing calls in tit species 


\section{Abstract}

Nest predation often leads to breeding failure, and is an important selective pressure of natural selection that affects nest defense behavior in birds. Many tit species give a hissing call for nest defense, but there are few studies on interspecific variation in hissing calls and whether these are related to nest predation and nesting success. In this study, we compared the hissing calls of five tit species including cinereous tit (Parus cinereus), marsh tit (Poecile palustris), varied tit (Sittiparus varius), willow tit (Poecile montanus), and coal tit (Periparus ater) in Saihanba National Forest Park in Hebei and Xianrendong National Nature Reserve in Liaoning. In Saihanba of Hebei, the proportion of individuals giving a hissing call and nest predation were similar among three tit species (cinereous, varied, and marsh tits). In Xianrendong of Liaoning, the proportion of cinereous, varied, and marsh tit individuals giving a hissing call differed significantly but nest predation did not. Cinereous and varied tits showed no differences in clutch size, date of the first egg, nest predation and nesting success between individuals that gave and those that did not give a hissing call. These results indicated that for tit species that breed in nest boxes distributed within the same area, there is interspecific variation in hissing calls, but these are not significantly correlated with nest predation risk.

Keywords: hissing call, nest defense, nest predation, repeatability, Paridae. 
Nest predation often leads to failed reproduction and is a major selective pressure that affects nest defense behavior in birds (Ricklefs 1969; Martin 1995; Forstmeier and Weiss 2004; Fontaine and Martin 2006; Lima 2009; Tilgar and

Moks 2015; Fu et al. 2016; Guppy et al. 2017). Birds have evolved complex anti-predation strategies to protect their nests and demonstrate specific behaviors when facing predators of different types and risk levels (Lima et al. 2005; Yorzinski and Vehrencamp 2009; Krams et al. 2010; Yorzinski and Platt 2012; Suzuki 2011, 2015; Daniela et al. 2018; Maziarz et al. 2018). For example, when blue peacock (Pavo cristatus) encounters a raccoon during the day, it calls loudly, stretches its neck, opens its wings, and strikes a flying pose as it approaches the predator. However, at night it will instead remain silent and give a soft hissing call (Yorzinski and Platt 2012).

In animals sound is often used to transmit predator information (Zuberbühler 2009; Fasanella and Fernández 2009; Suzuki 2011, 2014, 2015; Fuong et al. 2014; Townsend et al. 2014). Individuals of the same or different species use this acoustic information to evade predation (Sherman 1977; Pipia et al. 2009; Kitchen et al. 2010; Suzuki 2011, 2015; Gill and Bierema 2013; Townsend and Manser 2013). For example, Japanese tits (Parus minor) give different warning sounds to indicate the predator type: the "jar" sound is used to indicate a Japanese rat snake (Elaphe climacophora) whereas the "chicka" sound indicates a jungle crow (Corvus macrorhynchos) (Suzuki 2014). When 
67 chicks hear the "jar" sound coming from the female they jump out of the nest to evade predation by the snake, but upon hearing the "chicka" sound they instead huddle in the nest to avoid being preyed upon (Suzuki 2011).

Some birds have also developed acoustic Bayesian mimicry that simulates the sound of a toxic, inedible, or more dangerous species so as to gain security benefits (Gaul 1952; Sibley 1955; Klump and Shalter 1984; Apel and Weise 1986; Rowe et al. 1986; Owings et al. 2002; Kelly et al. 2008; Zub et al 2017). When it senses invasion by a predator, the bird stretches its wings forward and down rapidly in a curve, raises and extends its tail, and gives a spontaneous hissing call (Perrins 1979; Cramp and Perrins 1994) that leads to its

misidentification as a snake by the predator, which is then discouraged from approaching (Cox 1930; Sibley 1955; Rowe et al. 1986; Perrins 1979; Krams et al. 2014). For example, the hissing call of burrowing owl (Athene cunicularia) simulates the crackling sound of alerted Prairie rattlesnakes (Crotalus viridis) and is used to scare off its predator, the California ground squirrel (Spermophilus beecheyi) (Rowe et al. 1986).

Hissing calls are common in cavity breeding birds including tits (Odum 1942; Hinde 1952; Sibley 1955; Apel and Weise 1986; Broughton 2005, 2012). In many tit species, females incubate the eggs while males scarcely engage in alerting behavior or assist with nest defense (Perrins 1979). A recent study showed that hissing females of great tits (Parus major) survive better than silent females (Krams et al. 2014). Playing recordings of the hissing calls of the great 
tit, Eurasian blue tit (Cyanistes caeruleus), and marsh tit (Poecile palustris) affected nest exploration by their predators, the yellow-necked mouse (Apodemus flavicollis) (Zub et al. 2017). Among different tit species breeding in the same area, rates of nest predation are lower for those that exhibit hissing behavior than for those that do not (Walankiewicz 2002; Wesołowski 2002; Czeszczewik 2004; Wesołowski and Rowiński 2012; Maziarz et al. 2016). However, hissing calls of many tit species have not yet been investigated. Moreover, there is little information on whether there are interspecific variation in hissing calls of tit species located in the same area, and whether the hissing call of a species is related to its life history traits.

To address these questions, in this study we compared the hissing calls of five tit species located in the same area. For sympatric breeding cinereous and varied tits, we also investigated whether there are differences in the breeding parameters of individuals with or without a hissing call, such as date of the first egg, clutch size, nest predation rate and nesting success in order to determine the relationship between hissing call and breeding performance.

\section{Materials and methods}

\section{Study area and study species}

The Saihanba National Forest Park (SHB) is located in Weichang, $240 \mathrm{~km}$ from Chengde City, Hebei Province $\left(42^{\circ} 02^{\prime}-42^{\circ} 36^{\prime} \mathrm{N}, 116^{\circ} 51^{\prime}-117^{\circ} 39^{\prime} \mathrm{E}\right)$ at an altitude of 1,350-1,650 m. The park has a semi-arid/semi-humid cold- 
111

112

113

114

115

116

117

temperature continental monsoon climate and is the main natural secondary forest and plantation forest area in Hebei. Within the park there are plateaus, mountains, forests, and grasslands (Fig. 1; Liu et al. 2017).

The Xianrendong National Nature Reserve (XRD) is located in Zhuanghe, Liaoning Province $\left(39^{\circ} 54^{\prime}-40^{\circ} 03^{\prime} \mathrm{N}, 122^{\circ} 53^{\prime}-123^{\circ} 03^{\prime} \mathrm{E}\right)$ at an altitude of 200 $600 \mathrm{~m}$. It is adjacent to the Yellow Sea and is located in a warm, temperate, humid monsoon climate zone (Fig. 1; Du et al. 2010).

Tits belong to the Paridae family, which comprises small passerine birds that are mainly distributed in the Northern hemisphere and Africa. These small, stocky, woodland species have short bills and a length of 10-22 cm (Gosler and Peter, 2007). The great tit, which were originally distributed in Eurasia, are now classified as three separate species: great tits from Europe to Northwestern Asia, the cinereous tit (Parus cinereus) of South Asia, and the Japanese tit of East Asia (Päckert et al. 2005).

In 2018, the birds attracted to artificial nest boxes hung in SHB were mainly cinereous tits, willow tits (Poecile montanus), and coal tits (Periparus ater) (Fig. 1, A-C). Between 2016 and 2018, the birds that were attracted to nest boxes hung in XRD were mainly cinereous, marsh, and varied tits (Sittiparus varius) (Fig. 1, D-F).

\section{Field data collection}


132

The nest boxes, particularly those used by tits, were routinely examined during the breeding season. Hatching status was determined according to clutch size and date of the first egg. The date on which the female laid the last egg was defined as day 0 of the incubation period. In this study, the incubation period of each of the five tit species was approximately 12 days. We divided the incubation period into three stages: early, mid and late incubation. The nest box was inspected once during each stage. When we opened the lid of the nest box during the inspection, some of the tits gave a hissing call instead of escaping from the nest. Depending on the response of the female upon opening the nest box, we divided the birds into those with or without hissing calls. During the field work, we found that the hissing call behavior of the five tit species was highly repeatable - i.e., individuals that did not give a hissing call at the start of the study did not give any hissing calls during the whole breeding period. Nest predation rate was defined as the proportion of predated nests to the total nests monitored (Krams et al. 2014). Nesting success was defined as the proportion of successful nests (success to fledge at least one young), and it was a dichotomous variable for measuring predation intensity (Pribil 1998).

\section{Statistical analysis}

Statistical analysis was performed using SPSS v.16.0 for Windows (IBM, Armonk, NY, USA). The one-sample Kolmogorov-Smirnov test was used to analyze the normality of the data. When the data normality condition was met, 
154 the t-test or one-way analysis of variance was used to compare mean values.

155 Otherwise, non-parametric tests-i.e., the Mann-Whitney U test and Kruskal-

156 Wallis test - were used. All tests were two-tailed, with a significance level of $P$

$157<0.05$. Data are expressed as mean \pm standard deviation (mean $\pm \mathrm{SD})$.

158 The number of tits with hissing calls in the two study areas were as follows:

159 in SHB, 32 nests of cinereous tits, 17 nests of coal tits, and eight nests of willow

160 tits were found to give hissing calls in 2018. In XRD, 48 nests of varied tits and

16145 nests of cinereous tits in 2016; and 39 nests of varied tits, 40 nests cinereous

162 tits, and 17 nests of marsh tits in 2018 were found to give hissing calls. Since no

163 breeding of marsh tits was recorded in XRD in 2016, and the proportion of

164 varied tits giving hissing calls differed significantly between the 2 years, only

165 the 2018 data were included when analyzing interspecies differences of hissing

166 calls of tits located in the same area of Liaoning. However, both the 2016 and

167 the 2018 data were used when analyzing differences in the reproductive

168 parameters of birds with and without hissing calls.

170 Results

171 During 2018 in SHB, 19 out of 32 (59.4\%) cinereous tits, 14 out of 17 (82.3\%)

172 coal tits, and 3 out of $8(37.5 \%)$ willow tits gave hissing calls. There were no

173 significant differences among hissing calls of the three tit species located in the

174 same area (Fig. 2; $P=0.076$, Fisher's exact test). 
cinereous tits, and 3 out of 17 (17.6\%) marsh tits gave hissing calls. Significant

differences were observed among hissing calls of the three tit species located in the same area (Fig. 2; $P=0.011$, Fisher's exact test).

In SHB, none of the 66 cinereous tits and 45 coal tits and only one of the

31 willow tit nests were depredated. There were no significant differences in predation rates among the three tit species $(P>0.05$, Fisher's exact test). tits, and 8 out of $19(42.1 \%)$ marsh tits were targeted by predators. There were no significant differences in predation rates among the three tit species $(P=0$.

confirmed to be depredated by mice (10\%; 3 out of 30 nests) or snakes $(90 \%$; including Korean rat-snakes Elaphe anomala and steppe rat-snakes E. dione).

For cinereous tits, 62 tits gave hissing calls whereas 23 tits did not. The date of the first egg and clutch size did not differ significantly between the two groups of tits $[9.75 \pm 1.31(\mathrm{n}=60)$ vs. $9.77 \pm 1.23(\mathrm{n}=22)](P=0.880$, MannWhitney U test). Similar rates of nest predation (19.4\% vs. $30.4 \%)$ and nesting success (64.5\% vs. 52.2\%) were also observed between the two groups (Fig. 3; $P>0.05$, Fisher's exact test).

For varied tits, 52 tits gave hissing calls whereas 37 tits did not. The two groups were similar in terms of date of the first egg and clutch size $(7.31 \pm 1.08$ 196 vs. $7.10 \pm 1.12)(P=0.264$, Mann-Whitney $\mathrm{U}$ test $)$ as well as nest predation 
197

198

199

200

201

202

203

204

205

206

207

208

209

210

211

212

213

214

215

216

217

218

$(21.6 \%$ vs. $30.8 \%)$ and nesting success (56.8\% vs. $44.2 \%)$ (Fig. $3 ; P>0.05$, Fisher's exact test).

\section{Discussion}

Nest predation is one of the major causes of death in birds, and it has led to the evolution of morphological, physiological, and behavioral strategies to avoid predation (Lima 2009; Parejo et al. 2013; Fu et al. 2016). Previous work showed that cavity breeding tits give hissing calls to frighten approaching predators (Rowe et al. 1986; Zub et al. 2017) and thereby increase the survival rate of female birds and fledglings (Krams et al. 2014). Our study indicated that in SHB, there were no significant differences in the proportion of cinereous, willow, or marsh tit giving hissing calls. In contrast, in XRD, differences were observed in the proportions of cinereous, varied, and marsh tits. However, in both SHB of Hebei and XRD of Liaoning, nest predation rates of tits breeding in nest boxes located in the same area were similar. Cinereous and varied tits showed no differences in clutch size, date of the first egg, nest predation rate and nesting success between birds with and those without hissing calls.

Tit species in the wild are known to give hissing calls (Pickens 1928;

Sibley 1995). However, there has been few studies investigating interspecific variation in hissing calls of tit species (Sibley 1995; Krams et al. 2014; Koosa and Tilgar 2016; Zub et al. 2017). An early report suggested that the hissing calls of tits was an acoustic form of Bayesian mimicry and provided a brief 
description of the hissing calls of different species (Sibley 1995). In this study, we recorded in detail the hissing calls of five tit species located in the same area and investigated interspecific differences. In SHB of Hebei, we found that between cinereous and willow tits, there was no difference in the proportion of individuals giving a hissing call. However, in XRD of Liaoning, the proportions differed among cinereous, varied, and marsh tits. We found that $60 \%$ of individual cinereous tits gave a hissing call; this is comparable to the $70 \%$ reported in a previous study in which hissing calls of great tits were found to substantially reduce the predation rate of breeding females (Krams et al. 2014). The hissing call of tits was also shown to discourage nest exploration behavior of yellow-necked mouse (Apodemus flavicollis) (Zub et al. 2017). However, tit species differing in the proportion of individuals giving a hissing call did not have lower nest predation rate. In SHB, artificial nest boxes were mainly distributed in plantations located in areas where there were few snakes and Swinhoe's striped squirrels (Tamiops swinhoei) — two of the natural predators of tits - due to the high altitude and low temperature. In contrast, in XRD, nest predation rates of cinereous, varied, and marsh tits did not differ despite variation in the proportion of individuals with hissing calls. This is because the main nest predators in this area were Korean and steppe rat-snakes, which are not affected by the hissing calls of tits. The nest predation rate is markedly lower for great tits when compared to those without hissing calls (Krams et al. 2014). However, comparison of nest predation rates in cinereous and varied tits 
241

242

243

244

245

246

247

was similar for individuals with and without hissing calls. A possible reason for this discrepancy is our small sample size ( 85 cinereous and 89 varied tits vs. 477 samples in the study by Krams et al. 2014). Additionally, predators in their study were mainly European pine marten (Martes martes), least weasel (Mustela nivalis), and great spotted woodpecker (Dendrocopos major), which are more likely scared off by the snake-like hissing calls of great tits than the predators in our study area (mainly snakes).

Hissing calls are unrelated to the breeding performance of female birds (Koosa and Tilgar 2016). For example, females with and without hissing calls were found to lay a similar clutch size. Our results support this observation. Furthermore, we also determined that the hissing calls of all five tit species are unrelated to nest predation risk.

In conclusion, our results showed that hissing calls are common among sympatrically breeding tit species such as cinereous, willow, coal, marsh, and varied tits. In SHB of Hebei, the hissing calls of cinereous, willow, and coal tits showed no interspecific variation. In XRD of Liaoning, although the proportion of individuals giving hissing calls was higher in cinereous as compared to marsh tits, the two species had similar predation risk. In addition, the hissing calls of cinereous and varied tits were unrelated to nest predation risk or life history traits such as date of the first egg, clutch size and nesting success. The present study demonstrated the behavioral adaptations of different tit species to nest 
262 predation, which can in turn provide insight into the life history traits of 263 members of the Paridae family.

264 
265 Ethics. The experiments reported here comply with the current laws of China.

266 Fieldwork was carried out under the permission from Saihanba National Forest

267 Park and Xianrendong National Nature Reserve, China. Experimental

268 procedures were in agreement with the Animal Research Ethics Committee of

269 Hainan Provincial Education Centre for Ecology and Environment, Hainan

270 Normal University (permit no. HNECEE-2011-001).

272 Data accessibility. Data used in this study are available in Electronic

273 Supplementary Materials.

Authors' contributions. The research idea was developed from discussion with

APM. DW and WL designed the study; LZ, JL, ZG and LZ performed field

experiments; LZ and JL carried out laboratory and statistical analyses. JL wrote the draft manuscript, and WL and APM revised and improved the manuscript.

All authors approved the final submission.

Competing interests. The authors declare that they have no competing interests.

283 Funding. This work was funded by the National Natural Science Foundation of 284 China (no. 31772453 to WL and no. 31872231 to DW). 
286 Acknowledgments. We are grateful to the anonymous referees for their 287 constructive comments that significantly improved this manuscript. We thank 288 Saihanba National Forest Park and Xianrendong National Nature Reserve for 289 their help and cooperation, Chunlei Jing and Congying Zhang for their 290 assistance with field work. 
292

293

294

295

296

297

298

299

300

301

302

303

304

305

306

307

308

309

310

311

312

\section{References}

Apel KM, Weise CM. 1986. The hiss-display of nesting black-capped chickadees in captivity. Wilson Bulletin, 98: 320-321.

Broughton RK. 2005. Hissing display of incubating marsh tit and antipredator response of the young. British Birds, 98: 267-268.

Broughton RK. 2012. Nest defence behaviour by marsh tits in response to a stuffed weasel. British Birds, 105: 39-40.

Cox AHM. 1930. Nestling wood-warblers "hissing". British Birds, 23: 219-220.

Cramp S, Perrins CM. 1994. The birds of the western Palearctic. Oxford University Press, New York.

Czeszczewik D. 2004. Breeding success and timing of the pied flycatcher Ficedula hyploeuca nesting in natural holes and nest-boxes in the Białowieża forest, Poland. Acta Ornithology, 39: 15-20.

Daniela C, Sealy SG. 2018. Evolutionary significance of antiparasite, antipredator and learning phenotypes of avian nest defence. Scientific Reports, 8: 10569.

Du Y, Huo Y, Wan D, Sun J, Lv Y, Cao J. 2010. Moss selection as nest materials by Parus varius. Chinese Journal of Zoology, 45: 144-149.

Fasanella M, Fernández GJ. 2009. Alarm calls of the southern house wren Troglodytes musculus: Variation with nesting stage and predator model. Journal of Ornithology, 150: 853-863. 
313 Fontaine JJ, Martin TE. 2006. Parent birds assess nest predation risk and adjust their reproductive strategies. Ecology Letters, 9: 428-434.

315 Forstmeier W, Weiss I. 2004. Adaptive plasticity in nest-site selection in response to changing predation risk. Oikos, 104: 487-499.

317 Fu Y, Chen B, Dowell SD, Zhang Z. 2016. Nest predators, nest-site selection and nest success of the Emei Shan liocichla (Liocichla omeiensis), a vulnerable babbler endemic to southwestern China. Avian Research, 7: 18.

Fuong H, Keeley KN, Bulut Y, Blumstein DT. 2014. Heterospecific alarm calleavesdropping in nonvocal, white-bellied copper-striped skinks, Emoia cyanura. Animal Behaviour, 95: 129-35.

Gaul AT. 1952. Audio mimicry: An adjunct to color mimicry. Psyche, 59: 8283.

Gill SA, Bierema AMK. 2013. On the meaning of alarm calls: A review of functional reference in avian alarm calling. Ethology, 119: 449-461.

Gosler A, Clement P. 2007. Family Paridae (tits and chickadees). In del Hoyo J, Elliott A, Christie D (eds). Handbook of the birds of the world. Vol. 12: Picathartes to tits and chickadees. Pp. 662-709. Lynx Edicions, Barcelona. Guppy M, Guppy S, Marchant R, Priddel D, Carlile N, Fullagar P. 2017. Nest predation of woodland birds in south-east Australia: Importance of unexpected predators. Emu, 117: 92-96.

Hinde RA. 1952. The behaviour of the great tit (Parus major) and some other related species. Behaviour, 2 (Suppl.): 1-201. 
335 Kelly LA, Coe RL, Madden JR, Healy SD. 2008. Vocal mimicry in songbirds. Animal Behaviour, 76: 521-528.

337

Kitchen D, Bergman T, Cheney D, Nicholson J. 2010. Comparing responses of four ungulate species to playbacks of baboon alarm calls. Animal Cognition, 13: 861-870.

Klump GM, Shalter MD. 1984. Acoustic behaviour of birds and mammals in the predator context; I. Factors affecting the structure of alarm signals. II. The functional significance and evolution of alarm signals. Zeitschrift für Tierpsychologie, 66: 189-226.

Koosa K, Tilgar V. 2016. Is hissing behaviour of incubating great tits related to reproductive investment in the wild? Acta Ethologica, 19: 173-180.

Krams I, Krama T, Berzins A, Rantala MJ. 2010. The risk of predation favors cooperation among breeding prey. Communicative and Integrative Biology, 3: $243-244$.

Krams I, Vrublevska J, Koosa K, Krama T, Mierauskas P, Rantala MJ, Tilgar V. 2014. Hissing calls improve survival in incubating female great tits (Parus major). Acta Ethology, 17: 83-88.

Lima SL, Rattenborg NS, Lesku JA, Amlaner CJ. 2005. Sleeping under the risk of predation. Animal Behaviour, 70: 723-736.

Lima SL. 2009. Predators and the breeding bird: behavioral and reproductive flexibility under the risk of predation. Biological Reviews, 84: 485-513. 
Liu J, Ma L, Zhang Z, Gu D, Wang J, Li J, Gao L, Hou J. 2017. Maximum frequency of songs reflects body size among male dusky warblers Phylloscopus fuscatus (Passeriformes: Phylloscopidae). European Zoological Journal, 84: 186-192.

Martin TE. 1995. Avian life history evolution in relation to nest sites, nest predation, and food. Ecological Monograph, 65: 101-127.

Maziarz M, Piggott C, Burgess M. 2018. Predator recognition and differential behavioural responses of adult wood warblers Phylloscopus sibilatrix. Acta Ethologica, 21: 13-20.

Maziarz M, Wesołowski T, Hebda G, Cholewa M, Broughton RK. 2016. Breeding success of the great tit Parus major in relation to attributes of natural nest cavities in a primeval forest. Journal of Ornithology, 157: 343354.

Odum EP. 1942. Annual cycle of the black-capped chickadee. Auk, 59: 499531.

Owings DH, Rowe MP, Rundus AS. 2002. The rattling sound of rattlesnakes (Crotalus viridis) as a communicative resource for ground squirrels (Spermophilus beecheyi) and burrowing owls (Athene cunicularia). Journal of Comparative Psychology, 116: 197-205.

Parejo D, Avilés JM, Peña A, Sánchez L, Ruano F, Zamora-Muñoz C, MartínVivaldi M. 2013. Armed rollers: Does nestling's vomit function as a defence against predators? PLoS One, 8: e68862. 
Päckert M, Martens J, Eck S, Nazarenko AA, Valchuk OP, Petri B, Veith M. 2005. The great tit (Parus major): A misclassified ring species. Biological Journal of the Linnean Society, 86: 153-174.

Perrins CM. 1979. British tits. Collins, London.

Pickens AL. 1928. Auditory protective mimicry of the chicadee. Auk, 45: 302304.

Pipia A, Ciuti S, Grignolio S, Luchetti S, Madau R, Apollonio M. 2009. Effect of predation risk on grouping pattern and whistling behaviour in a wild mouflon Ovis aries population. Acta Theriologica, 54: 77-86.

Ricklefs RE. 1969. An analysis of nesting mortality in birds. Smithsonian Contributions to Zoology, 9: 1-48.

Rowe MP, Coss RG, Owings DH. 1986. Rattlesnake rattles and burrowing owl hisses: A case of acoustic Batesian mimicry. Ethology, 72: 53-71.

Sherman PW. 1977. Nepotism and the evolution of alarm calls. Science, 197: 1246-53.

Sibley CG. 1955. Behavioral mimicry in the titmice (Paridae) and certain other birds. Wilson Bulletin, 67: 128-132.

Suzuki TN. 2011. Parental alarm calls warn nestlings about different predatory threats. Current Biology, 21: R15-R16.

Suzuki TN. 2014. Communication about predator type by a bird using discrete, graded and combinatorial variation in alarm calls. Animal Behaviour, 87: $59-65$. 
400

401

402

403

404

405

406

407

408

409

410

411

412

413

414

415

416

417

418

419

420

Suzuki TN. 2015. Assessment of predation risk through referential communication in incubating birds. Scientific Reports, 5: 10239.

Tilgar V, Moks K. 2015. Increased risk of predation increases mobbing intensity in tropical birds of French Guiana. Journal of Tropical Ecology, 31: $243-250$.

Townsend SW, Charlton BD, Manser MB. 2014. Acoustic cues to identity and predator context in meerkat barks. Animal Behaviour, 94: 143-149.

Townsend SW, Manser MB. 2013. Functionally referential communication in mammals: The past, present and the future. Ethology, 119: 1-11.

Walankiewicz W. 2002. Nest predation as a limiting factor to the breeding population size of the collared flycatcher Ficedula albicollis in the Białowieża National Park (NE Poland). Acta Ornithology, 37: 91-106.

Wesołowski T. 2002. Antipredator adaptations in nesting marsh tits Parus palustris: the role of nest site security. Ibis, 144: 593-601.

Wesołowski T, Rowiński P. 2012. The breeding performance of blue tits Cyanistes caeruleus in relation to the attributes of natural holes in a primeval forest. Bird Study, 59: 437-448.

Yorzinski JL, Platt ML. 2012. The difference between night and day: antipredator behavior in birds. Journal of Ethology, 30: 211-218.

Yorzinski JL, Vehrencamp SL. 2009. The effect of predator type and danger level on the mob calls of the American crow. Condor, 111: 159-168. 
421 Zub K, Czeszczewik D, Ruczyński I, Kapusta A, Walankiewicz W. 2017.

422 Silence is not golden: The hissing calls of tits affect the behaviour of a nest 423 predator. Behavioral Ecology and Sociobiology, 71: 79.

424 Zuberbühler K. 2009. Survivor signals: The biology and psychology of animal 425 alarm calling. Advance in the Study of Behaviour, 40: 277-322.

426 Zheng G. 2017. A checklist on the classification and distribution of the birds of 427 China (Third Edition). Science Press, Beijing. 
Legends to figures

430

431 Figure 1. Study areas and study species in this study. Capital letters (A-F) refer 432 to bird species and lower case letters (a-f) refer to nest and eggs. A and D refer 433 to cinereous tit; $\mathrm{B}$ refers to coal tit; $\mathrm{C}$ refers to willow tit; E refers to varied tit; 434 and $\mathrm{F}$ refers to marsh tit.

435

436

Figure 2. Proportion of hissing individuals in five tit species at two study sites.

437

438 Figure 3. Comparison of nesting success between individuals with hissing call 439 and individuals without hissing call in cinereous and varied tits.

440 


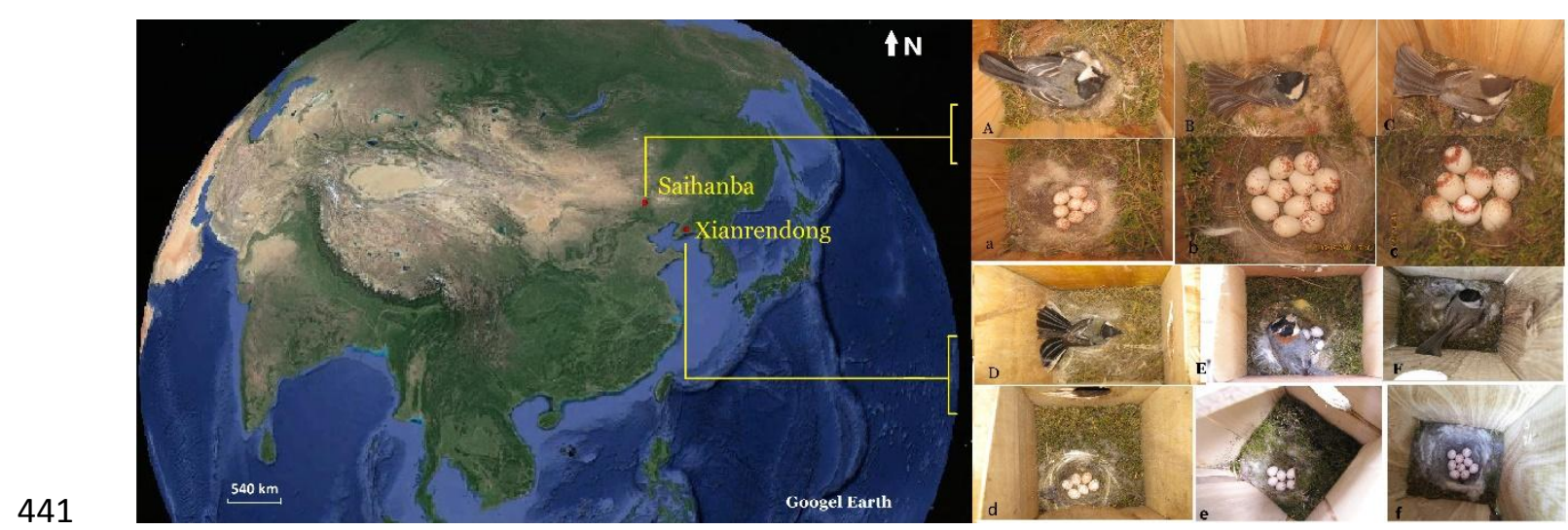

442 Fig. 1

443 


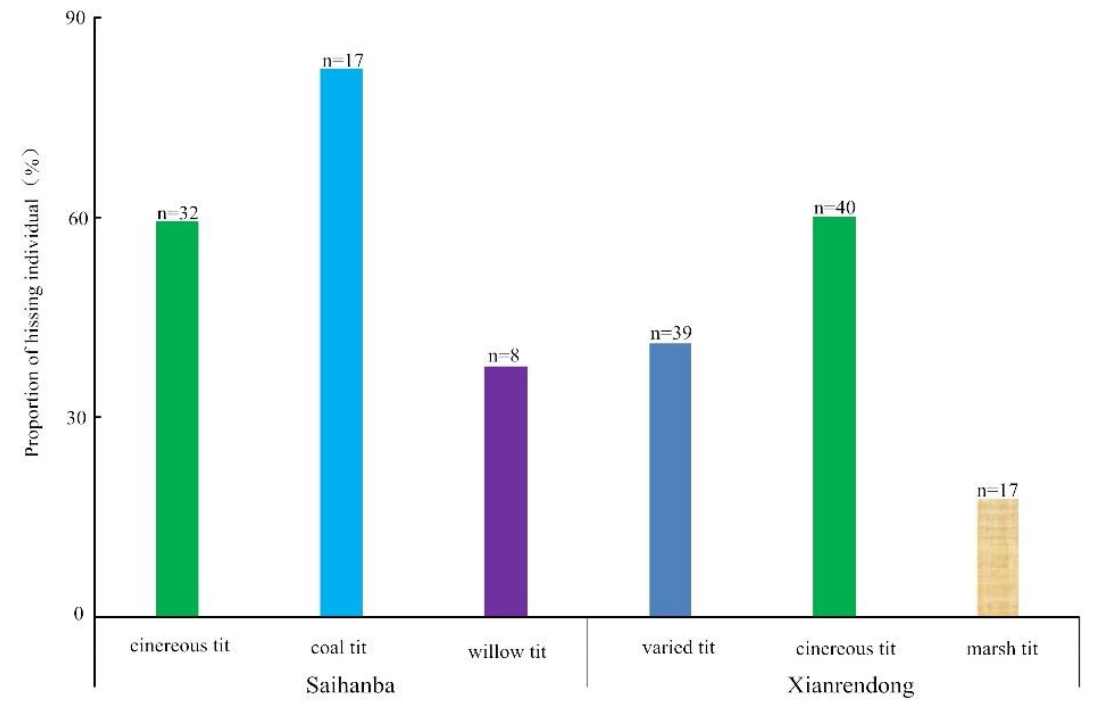

444

445 Fig. 2

446 


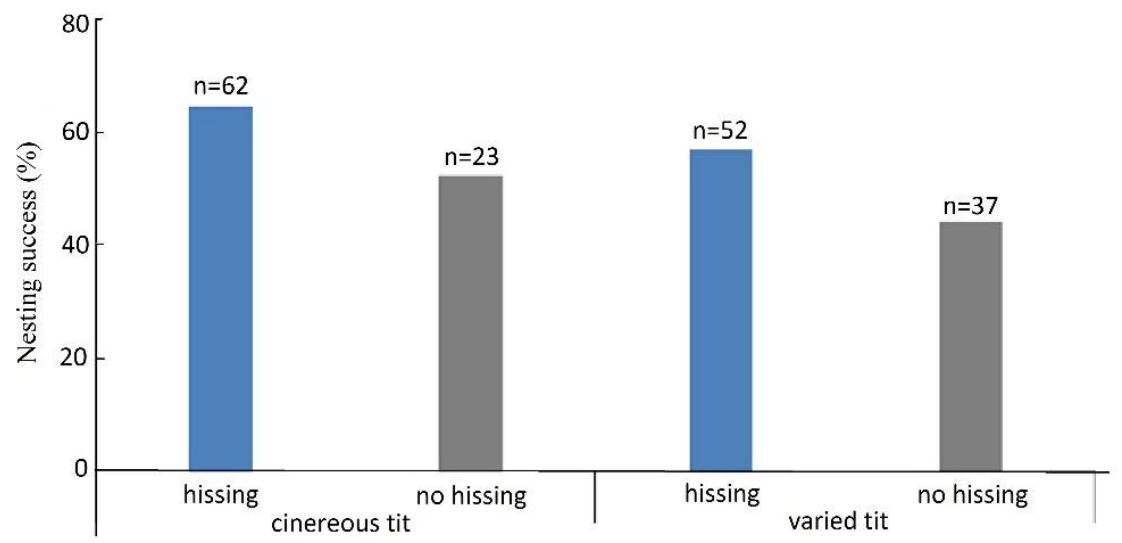

$448 \quad$ Fig. 3 